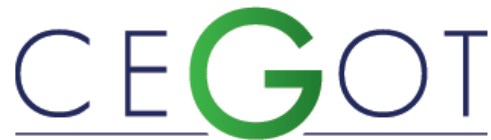

Centro de Estudos de Geografia e Ordenamento do Território
Geografia e Ordenamento do Território, Revista Eletrónica Centro de Estudos de Geografia e Ordenamento do Território http://cegot.org FerReira, HeLoísA Universidade Estadual Paulista, Campus de Presidente Prudente 19060-900, Rua Roberto Simonsen, 305, Centro Educacional, Presidente Prudente, Brasil heloisamariz@gmail.com

\title{
O centro principal em estruturas policêntricas: transformações e permanências em cidades médias paulistas
}

The main centre in polycentric city structures: transformations and maintenance in mediumsized cities of São Paulo state

Referência: Ferreira, Heloísa (2018). O centro principal em estruturas policêntricas: transformações e permanências em cidades médias paulistas. Revista de Geografia e Ordenamento do Território (GOT), n. ${ }^{\circ} 15$ (dezembro). Centro de Estudos de Geografia e Ordenamento do Território, p. 199-229, dx.doi.org/10.17127/got/2018.15.009

\section{RESUMO}

Originária do incremento de funções a centros urbanos, na rede urbana, a estruturação policêntrica implica, na escala intraurbana, em relações de concorrência e complementaridade entre áreas centrais, que embora acarretem complexidade à identificação de um centro principal, consistem em mudanças que se combinam a condições preexistentes, em tendência à permanência do centro da cidade como principal espaço de consumo. A partir de Marília, Presidente Prudente e São Carlos, situadas no estado de São Paulo, Brasil, buscamos apreender o centro principal de cidades médias, que exibiram novas funções e, com isso, redefinição de lógicas e práticas espaciais nos espaços intraurbanos. Entre transformações e permanências, identificamos manutenção do centro enquanto centro principal em Marília e São Carlos e tênue hierarquia de áreas centrais em Presidente Prudente.

Palavras-chave: centro da cidade; centro principal; policentralidade; cidades médias.

\section{ABSTRACT}

As a result of the increase of the functions of the urban centers within the urban network, polycentric structuring implies, on an intra-urban scale, both competitive and complementarity relations among central areas. While this diversification entails complexity in the identification of a main center, the tendency is for the city center to remain the main space of consumption. Starting with Marília, Presidente Prudente, and São Carlos, located in the state of São Paulo, Brazil, we sought to identify the main centers of medium-sized cities, which exhibited new functions and redefined spatial logics and practices in intra-urban spaces. Between transformations and permanency, we identified the maintenance of the city center as the main hub in Marília and São Carlos and a tenuous hierarchy of central areas in Presidente Prudente. 
Keywords: city center; main center; polycentrality; medium-sized cities.

\section{Introdução ${ }^{1}$}

No presente artigo, analisamos o centro principal de cidades médias que exibiram, nas últimas décadas do século $X X$, redefinições importantes na estrutura e centralidade intraurbana, no desenrolar do processo de policentrismo. Nosso estudo se fez por meio da compreensão de lógicas espaciais de empresas e práticas espaciais de consumo de citadinos, das cidades paulistas de Marília, Presidente Prudente e São Carlos, que consistem em centros urbanos com novos papéis na rede urbana.

Como explicações introdutórias, trataremos, brevemente, das dinâmicas que contribuem para tais transformações, perpassando por noções que utilizamos nos tópicos seguintes, sucedidas pelo detalhamento dos procedimentos metodológicos privilegiados e pela descrição da organização do texto.

De início, destacamos o entendimento acerca do policentrismo. Compreendemos o processo enquanto representativo do incremento de relações não subordinadas ao centro da cidade. Consistem em relações de complementaridade, nas quais não observamos primazia de áreas centrais sobre outras, e de relações de concorrência ao centro, em que verificamos sobreposição da importância de áreas centrais frente ao centro da cidade, exercidas, por exemplo, por hipermercados e shopping centers, implantados nas cidades que analisamos, a partir da década de 1980.

A apreensão de tais relações nos permite tratar do policentrismo também em espaços intraurbanos, em paralelo ao processo em escalas regionais e metropolitanas, conferindo realce, sem desconsiderar distinções conforme as dimensões em que se realiza, ao seu atributo multiescalar, entendendo que resulta, sobretudo, de centralização econômica, sobre a qual damos ênfase, em função da temática de nossa análise, aos grandes grupos varejistas, que expandem suas escalas de atuação.

As dinâmicas de centralização do capital são entendidas, com base em Lencioni (2008), enquanto maior controle da gestão dos ciclos de valorização. Isso se soma à

\footnotetext{
${ }^{1}$ A autora agradece o financiamento da Fundação de Amparo à Pesquisa do Estado de São Paulo (FAPESP), processo no 2016/03757-3.
} 
desconcentração espacial de grandes grupos econômicos, que exibem maior diversidade de suas escolhas, segundo Sposito e Sposito (2017), com a atuação também em cidades não metropolitanas, especialmente cidades médias. Segundo esses dois autores, tais grupos consideram os importantes papéis exercidos por essas cidades, no âmbito da rede urbana, por atenderem não somente seu quadro populacional, como também de suas áreas de influência, mais ou menos abrangentes conforme suas situações geográficas.

Nossa compreensão de lógicas espaciais está apoiada em Sposito e Sposito (2017), conforme os quais, tais lógicas consistem em ações de grupos empresariais atinentes a escolhas locacionais de suas unidades, em decisões por centros urbanos e áreas centrais em que se considera diferentes variáveis, identificadas a partir de estudos prévios.

As cidades médias que analisamos, Marília, Presidente Prudente e São Carlos, estão situadas no estado de São Paulo, Brasil, e contam com população urbana, respetivamente, de 207.373, 203.370 e 213.070 habitantes $^{2}$. Ao pesquisarem as três cidades, Sposito e Góes (2013) identificaram papéis regionais distintos, sendo Presidente Prudente e Marília centros urbanos de superiores níveis hierárquicos, ao passo que São Carlos exibe posição inferior.

Segundo Sposito e Góes (2013, p. 36), Presidente Prudente apresenta maiores funções, sendo único centro urbano no Sudoeste paulista que atende 57 outros centros menos importantes, em parcela menos densa da rede urbana paulista. Marília exibe considerável área de influência, em níveis, contudo, inferiores a Presidente Prudente. Já São Carlos está situado em porção mais densa do estado, próximo a importantes cidades médias, como Araraquara, com a qual integra aglomeração não metropolitana, e Ribeirão Preto, e às metrópoles de Campinas e São Paulo, exibindo, com efeito, menor alcance espacial na rede urbana.

Escolhemos as três cidades para a nossa análise devido às suas similaridades e suas diferenças, que nos propiciaram a apreensão de elementos universais e particulares. As similaridades entre as três cidades dizem respeito ao porte demográfico, ao tipo urbano de cidades médias e às mudanças na centralidade intraurbana, com a implantação de novos espaços de consumo. Já as diferenças estão atreladas às localizações no estado de São Paulo, ao montante de investimentos realizados por grandes grupos varejistas, por meio da

\footnotetext{
${ }^{2}$ Conforme o Censo demográfico de 2010, realizado pelo Instituto Brasileiro de Geografia e Estatística (IBGE).
} 
instalação de hipermercados, shopping centers, franquias e filiais, e intensidade da reestruturação espacial observada nas três cidades.

Se as novas lógicas espaciais de empresas implicam, no que concerne à rede urbana, mudanças nos papéis de centros urbanos, no âmbito dos espaços intraurbanos promovem a reestruturação, com a emergência de novas áreas centrais, a exemplo de ações tomadas por agentes imobiliários, na implantação de shopping centers, e no reforço de seus papéis, como a instalação de franquias e filiais, por empresas que expandem suas escalas de atuação.

$\mathrm{Na}$ dimensão escalar dos espaços intraurbanos, as novas lógicas espaciais de empresas suscitam e são condicionadas por redefinição de práticas espaciais de consumo, que dizem respeito a escolhas de citadinos, quanto às áreas centrais de realização de compras e aquisição de serviços, no que podemos considerar, nos termos propostos por Lefebvre (1991), quando trata da noção de práticas espaciais, realidade urbana, atinente aos percursos realizados na cidade, e realidade cotidiana, em mudanças nos usos do tempo, que apreendemos com a frequência de tais práticas.

Enquanto escolhas atinentes aos espaços de compras, a redefinição de tais práticas espaciais está atrelada ao papel do consumo na sociedade contemporânea, instrumentalizado para distinção social e pertencimento a grupos, como assinalou Baudrillard (1991), o que promove, em associação a empresas que buscam públicos mais restritos, segmentação socioespacial dos espaços de consumo.

Numa articulação entre lógicas e práticas espaciais, destacamos que alguns dos grandes grupos varejistas promovem, na expansão de suas escalas de atuação e das camadas sociais que atendem, o incremento do crédito e do endividamento, com a oferta, em fusão ou incorporação a bancos, de diversos serviços, como apontou Sciré (2011), que envolvem a concessão de cartões e empréstimos, o que tem resultado em modificações de práticas de consumo de diferentes segmentos socioeconômicos, conforme salientou Montenegro (2014).

Além do fomento do crédito pelo setor privado, o Estado brasileiro tem atuado, nas últimas décadas, no estímulo ao consumo, por meio, dentre outras ações, da redução do Imposto sobre Produtos Industrializados (IPI) e da liberação do Fundo de Garantia por Tempo de 
Serviço (FGTS), contribuindo, nesse sentido, para o alargamento de camadas sociais que participam da expansão do consumo.

As transformações em lógicas e práticas espaciais se combinam a divisões territoriais do trabalho pretéritas, com elevada aglomeração e diversidade de atividades no centro da cidade, e continuidade de expressivo fluxo de pessoas ao centro, que exerce condição preexistente, com base em Santos (1996), ao processo de policentrismo.

Feita a explanação acerca das noções que utilizamos e das dinâmicas que contribuem para as mudanças na estrutura e centralidade intraurbana, frisamos, com isso, que nosso objetivo, no presente texto, consiste em analisar o centro principal, com privilégio para as dimensões da troca e do consumo, das cidades de Marília, Presidente Prudente e São Carlos, representativas de contextos espacial e temporal que se distinguem de estruturas espaciais pretéritas, em amálgama entre transformações e permanências.

Para isso, enfocamos, nos próximos parágrafos, os procedimentos metodológicos usados. Como instrumento de reconhecimento das áreas centrais presentes nas três cidades, utilizamos, inicialmente, o Cadastro Nacional de Endereços para Fins Estatísticos (CNEFE) ${ }^{3}$, em que conferimos os setores censitários ${ }^{4}$ de maiores concentrações de estabelecimentos. Entretanto, como os setores censitários correspondem a áreas contíguas que abrangem, em alguns casos, eixos viários de pouca aglomeração de comércio e serviços, realizamos trabalhos de campo para o ajuste da delimitação das diferentes áreas centrais.

A partir disso, valemo-nos da identificação do porte e da diversidade de atividades econômicas, por meio da coleta de dados do uso do solo no CNEFE e organização conforme a Classificação Nacional de Atividades Econômicas (CNAE) ${ }^{5}$; e identificação de franquias e

\footnotetext{
${ }^{3}$ O CNEFE constitui banco de dados de endereços de municípios brasileiros, elaborado pelo IBGE, quando do Censo de 2010. Nesse banco, é possível manejar grande número de informações, de que são ilustrativos logradouro e uso do imóvel (residencial ou comercial, por exemplo), organizados em setores censitários. 0 banco de dados está disponível no endereço eletrônico: http://www.censo2010.ibge.gov.br/cnefe/.

${ }^{4}$ Setor censitário constitui uma unidade territorial implantada pelo IBGE, no intuito de organização da coleta de informações nos censos demográficos e, posteriormente da agregação e tratamento dos dados, quando da disponibilização ao público.

${ }^{5} \mathrm{O}$ CNAE consiste em classificação de atividades econômicas elaborada pela Comissão Nacional de Classificação (CONCLA), pertencente ao IBGE, passível de consulta no site http://www.cnae.ibge.gov.br/. Essa classificação é organizada em seções, divisões, grupos, classes e subclasses, em que selecionamos para a pesquisa, seções e classes, por nos permitirem perspectiva ampla e também maior minúcia da organização.
} 
filiais $^{6}$, através da realização de trabalhos de campo em áreas centrais e coleta de informações em sítios eletrônicos de shopping centers, para apreensão da complexidade do capital das empresas situadas nas diferentes áreas centrais.

Também analisamos questionários ${ }^{7}$, aplicados em instituições de ensino públicas e privadas, somando 176, em Marília, 186, em Presidente Prudente, e 186, em São Carlos; e entrevistas com citadinos de distintos perfis, atinentes, por exemplo, ao bairro de moradia, nível de rendimento, gênero e estado, constituindo 17 entrevistas em Marília, 14, em Presidente Prudente, e 15, em São Carlos. As informações propiciadas por tais procedimentos metodológicos foram coletadas na Plataforma de Gerenciamento de Informações, do Projeto Temático que fizemos parte, "Lógicas econômicas e práticas espaciais contemporâneas: cidades médias e consumo".

Organizamos o texto em três seções. Na primeira, intitulada "Coexistências e articulações de áreas centrais", detalhamos a estrutura espacial das três cidades de nosso recorte territorial, fazendo uso de contribuições de Milton Santos (1985, 1994a, 1994b, 1994c, 1996), na abordagem das diferentes áreas centrais, considerando o que o autor denomina por eixo das coexistências, ligado a eixo das sucessões.

Para a operacionalização dessa análise discorremos acerca de nossa compreensão de relações de complementaridade e concorrência que são características do policentrismo, valendo-nos de importantes contribuições de pesquisadores que analisaram o processo nas escalas regional e metropolitana, bem como daqueles que se debruçaram sobre contextos de espaços intraurbanos de cidades médias brasileiras.

No item subsequente, "Novas relações entre áreas centrais e o centro principal", analisamos o centro principal de Marília, Presidente Prudente e São Carlos, por meio da compreensão de lógicas espaciais de empresas e práticas espaciais de consumo de citadinos, que nos proporcionou averiguar as relações entre as áreas centrais e as estruturas disso resultantes,

\footnotetext{
${ }^{6}$ As filiais consistem, de acordo com Silva e Azevedo (2007), em unidades pertencentes a um único agente econômico, que exerce comando por sede central, ao passo que franchising diz respeito, segundos os mesmos autores, ao intercâmbio, por meio de taxa de franquias e outras cobranças, de marca e sistema de gerenciamento, fornecido pelo franqueador ao franqueado. A coleta de dados de franquias e filiais foram coletados, em Marília, nos dias 22 e 23/01/2015 e 24 a 26/09/2017; em Presidente Prudente, 30 e 31/01/2015 e 02 e 03/10/2017; e, em São Carlos, em 27 a 29/11/2017.

${ }^{7}$ Entre as questões que compuseram os questionários e entrevistas estão o bairro de moradias, as lojas ou áreas centrais mais visitadas e a frequência das práticas de consumo. Ambos os procedimentos metodológicos foram realizados entre os anos de 2012 e 2015.
} 
hierárquicas e não hierárquicas. Por fim, sintetizamos nossos apontamentos, no tópico "Considerações finais".

\section{Coexistências e articulações de áreas centrais}

De modo geral, o centro da cidade exibiu, especialmente em contextos espaciais de um único centro ou de formação de áreas centrais secundárias, grande diversidade de atividades econômicas, especialmente de empresas de grandes capitais, como apontou Corrêa (1989), numa ímpar aglomeração de coisas, pessoas e informações e expressiva convergência de citadinos, de acordo com Lefebvre (1999).

Mais recentemente, entretanto, a produção do espaço urbano tem sido representativa, em diferentes cidades, de complexificação da estrutura espacial, características de várias áreas centrais, de considerável aglomeração de atividades, capitais externos e consumidores, em relações de complementaridade e concorrência ao centro.

Com efeito, entendemos que as diferentes áreas centrais pertencem a um eixo das coexistências, com base em Santos (1996), formadas em períodos discrepantes, num eixo das sucessões, segundo o mesmo autor, que afirma.

[...] no espaço geográfico, se as temporalidades não são as mesmas, para os diversos agentes sociais, elas todavia se dão de modo simultâneo. Constatamos, de um lado, uma assincronia na sequência temporal dos diversos vetores e, de outro, a sincronia de sua existência comum, num dado momento. $O$ entendimento dos lugares, em sua situação atual e em sua evolução, depende da consideração do eixo das sucessões e do eixo das coexistências (SANTOS, 1996, p. 159).

As estruturas espaciais de Marília, Presidente Prudente e São Carlos são marcadas, como podemos verificar nos mapas 1, 2 e 3, pelo centro da cidade, subcentros, eixos de desdobramento da área central, eixos de comércio e serviços ausentes de especialização funcional e/ou socioeconômica, shopping centers, hipermercados e, no caso de São Carlos, de Novo centro, conforme denominação utilizada por alguns dos citadinos entrevistados, formado pela expansão do centro, com tendência à especialização funcional e socioeconômica.

Os subcentros das três cidades estão situados na periferia, característica que favorece a aglomeração de atividades terciárias, em razão da distância de grandes bairros residenciais 
em relação ao centro, como já apontado por Villaça (1998), ao analisar grandes metrópoles brasileiras. Corrêa (1989) destacou, quando estudou a cidade do Rio de Janeiro, que os subcentros são característicos de relativa diversidade de bens e serviços oferecidos, porém em concentração inferior ao centro. Ao também analisar o Rio de Janeiro, Duarte (1974) salienta que os subcentros exibem aglomeração significativa de oferta de bens e serviços de demanda frequente, como padarias e açougues.

São ilustrativos dessa caracterização os subcentros dos bairros Nova Marília e Santa Antonieta, em Marília; Ana Jacinta e COHAB, em Presidente Prudente; e Santa Felícia e Cidade Aracy, em São Carlos. Já os subcentros do Jardim Bongiovani e da Vila Prado, em Presidente Prudente e São Carlos, respectivamente, exibem, além de significativa aglomeração e diversidade de atividades, presença de algumas franquias e filiais, representativas da atuação de empresas de maiores porte e complexidade do capital.

Os eixos de comércio e serviços são resultantes de lógicas espaciais de empresas interessadas na infraestrutura viária e no fluxo de veículos, como assinalou Berry (1958). Dentre tais espaços de consumo, surgiram, conforme Whitacker (1991, 1997), concentrações de atividades especializadas, funcional e/ou socioeconomicamente, que promovem convergência de fluxos de consumidores do conjunto da cidade, segundo Sposito (1991), conformando o que ambos os autores denominam por eixos de desdobramento da área central.

Nas três cidades que analisamos, constituem eixos de desdobramento da área central, em razão de especializações funcional e/ou socioeconômica, as vias Rio Branco, Coronel Galdino de Almeida e das Esmeraldas, em Marília; Coronel José Soares Marcondes, Washington Luiz e Brasil, em Presidente Prudente; e São Carlos, em São Carlos. Já as vias Tiradentes, Vicente Ferreira, Brigadeiro Eduardo Gomes, República e Pedro de Toledo, em Marília; Coronel Albino, 11 de Maio e 14 de Setembro, São Paulo e Antônio Rodrigues, em Presidente Prudente; e Iwagiro Toyama, Miguel Petroni e Miguel João e Antônio Blanco, em São Carlos, correspondem a incipientes aglomerações de atividades, com dinâmicas pouco consolidadas de especialização.

Implantadas mais recentemente, a instalação de grandes superfícies comerciais e de serviços se deu nos anos de 1980, quando, em Presidente Prudente, ocorreu a inauguração 
do Shopping Center Americanas, em 1986, atualmente Parque Shopping Prudente, propriedade da General Shopping Brasil, seguido do Prudenshopping, em 1990. Em ambos os espaços de consumo, estão também situados hipermercados, sendo no primeiro, o SuperMuffato, e no segundo, o Carrefour.

Em Marília, há também dois shopping centers, o Marília Shopping, em princípio condomínio de lojistas, teve suas atividades iniciadas em 2000, administrado por empresa externa, de atuação nacional, a AD Shopping. O segundo shopping center corresponde ao Esmeralda Shopping, implantado em 2004, por capitais locais, mas que tem atraído, assim como o Marília Shopping, segundo Melazzo (2012), investimentos externos.

Em São Carlos, apenas um shopping center foi implantado, em 1997, o Shopping Iguatemi São Carlos, propriedade da Iguatemi Empresa de Shopping Centers, com escala nacional de atuação. Nesse empreendimento, está situado o hipermercado Extra.

Cabe destacar que nas cidades com mais de um shopping center, que correspondem a Marília e Presidente Prudente, identificamos significativa expressão de centralidade e atração de capitais externos, por meio de franquias e filiais, do Marília Shopping e Prudenshopping, ao passo que o Esmeralda Shopping e o Parque Shopping Prudente contam com número inferior de lojas.

Além de shopping centers, Marília, São Carlos e, notadamente, Presidente Prudente contam com hipermercados. Nesta cidade, há sete hipermercados, incluindo 'atacadões', todos de capitais externos, a exemplo do Carrefour, de atuação internacional, e SuperMuffato e Muffato Max, do grupo Irmãos Muffato \& Cia, de atuação regional. Em Marília, o número de hipermercados é significativamente inferior, com três destes empreendimentos, e dois, em São Carlos, sendo igualmente de capitais externos.

É possível, com esses apontamentos, tecermos uma análise temporal das transformações na estrutura espacial das cidades de nosso recorte territorial. Embora as três cidades tenham exibido o surgimento de novas áreas centrais e a redefinição da centralidade intraurbana, a partir das duas últimas décadas, é Presidente Prudente que apresenta precedência, uma vez que a implantação de shopping centers se deu já em meados dos anos 1980. Em São Carlos, a instalação dessa tipologia de espaço de consumo ocorreu na década seguinte e, em Marília, nos anos 2000. 
Com efeito, a redefinição do centro e da centralidade intraurbana que advém da implantação de shopping centers e hipermercados se realiza de modo mais consolidado em Presidente Prudente, com considerável capacidade de oferta de bens e serviços, por empresas de elevada complexidade do capital, e atração de consumidores de dois importantes shopping centers, especialmente o Prudenshopping, e de notável número de hipermercados.

Os shopping centers consistem em espaços de considerável concentração, segundo Pintaudi (1989), de lojas, de bens e serviços similares, como grande número de lojas do vestuário, e distintos, a exemplo de lanchonetes, lojas de calçados e drogarias. De modo semelhante, os hipermercados oferecem, conforme Silva (2005) e Gomes (2017), expressiva variedade de artigos, desde hortaliças, alimentos industrializados, pneus e rações, e alguns serviços, como alimentos prontos, a partir, entretanto, de um único estabelecimento.

Chamamos atenção, nos mapas que se seguem, para a localização de áreas centrais na periferia geométrica das três cidades, no que se refere a subcentros e, sobretudo, a hipermercados e aos shopping centers Marília Shopping, Prudenshopping e Shopping Iguatemi São Carlos, não dependentes, segundo Sposito (2013), de centralidades já constituídas pela formação da cidade, no tempo longo, em ações que, em função da magnitude de seus impactos, prescindem da centralidade do centro. 


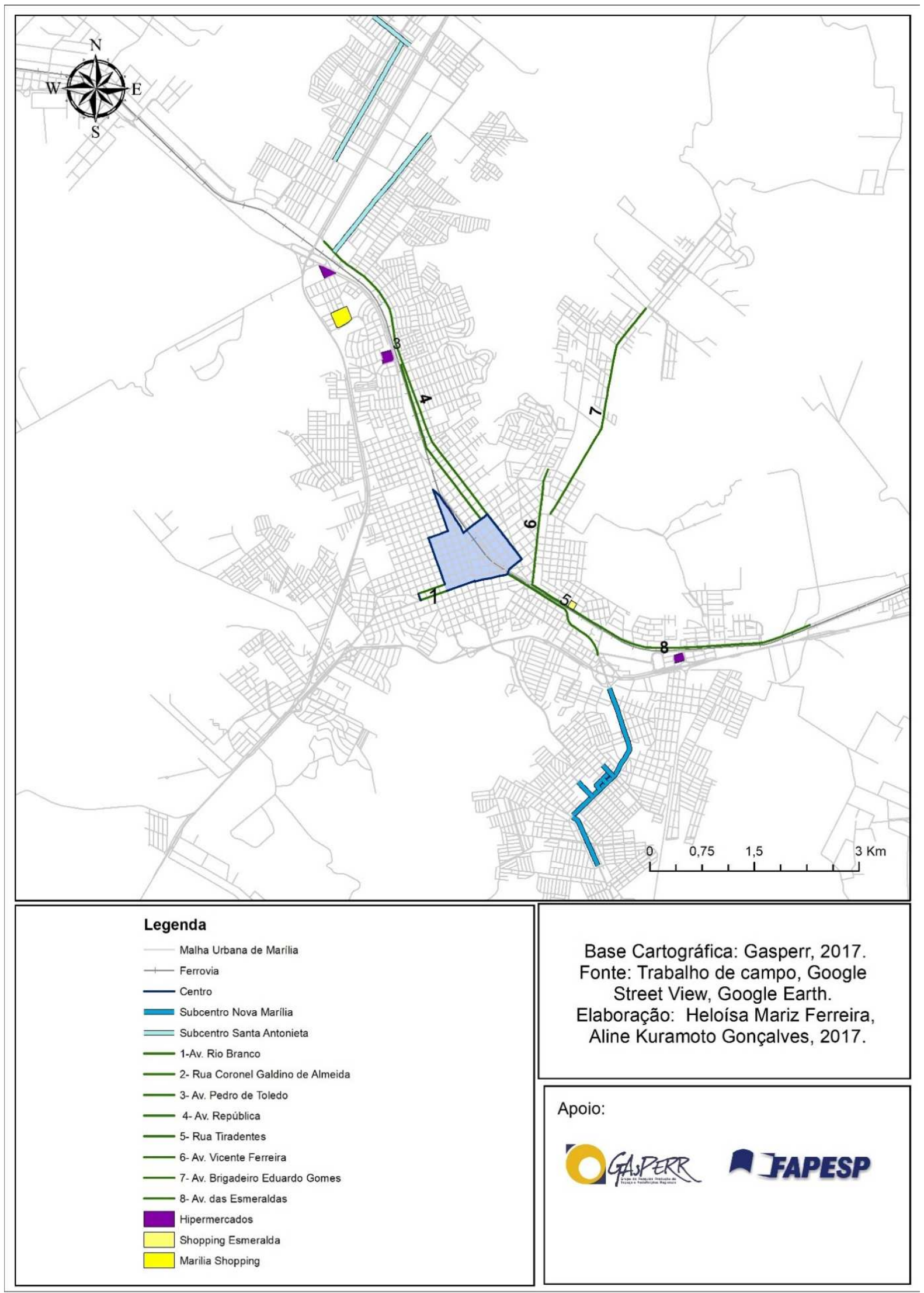

Figura 1 - Marília (SP). Áreas centrais, 2017. Extraído de Ferreira (2018) 


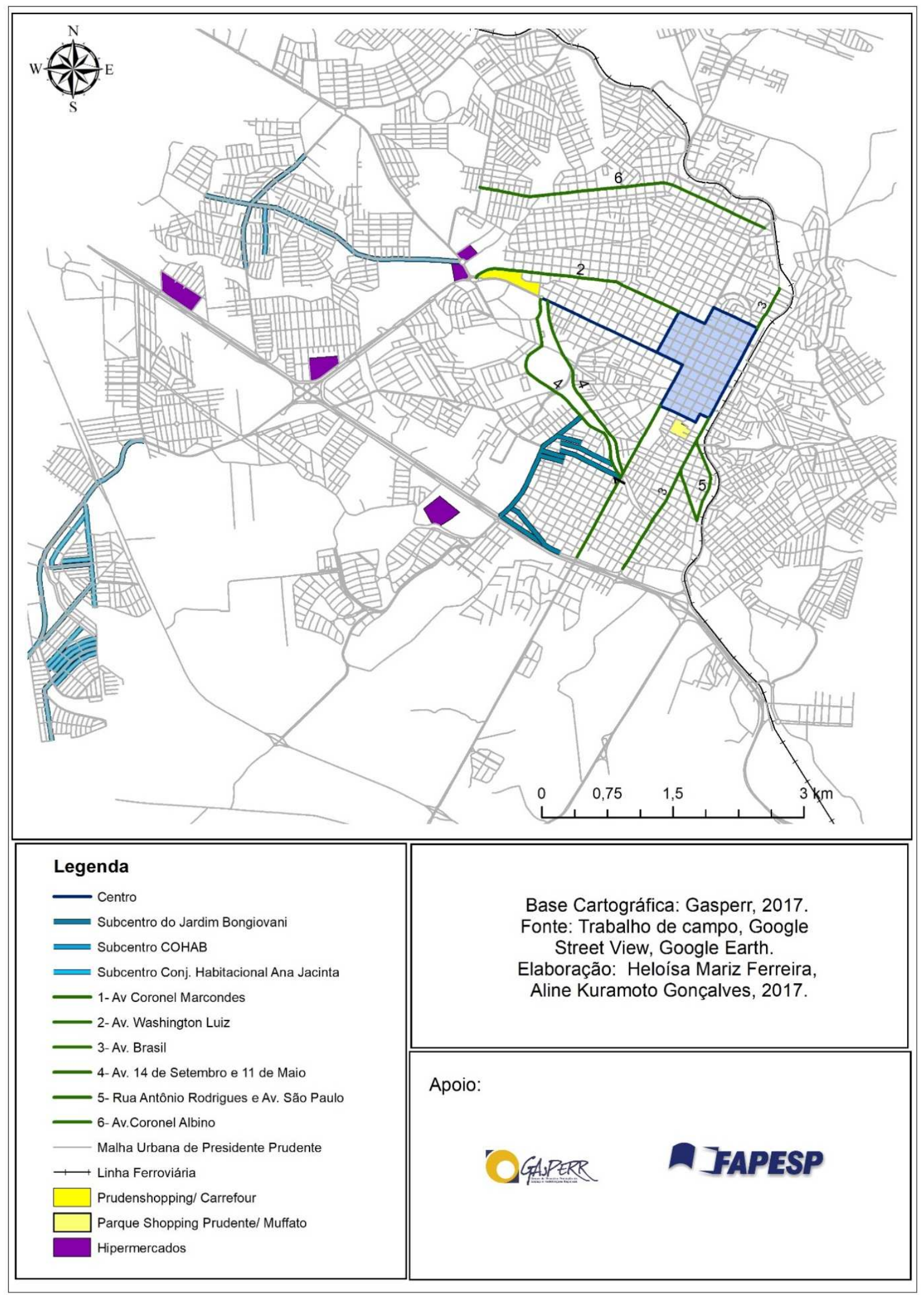

Figura 2 - Presidente Prudente (SP). Áreas centrais, 2017.

Extraído de Ferreira (2018) 


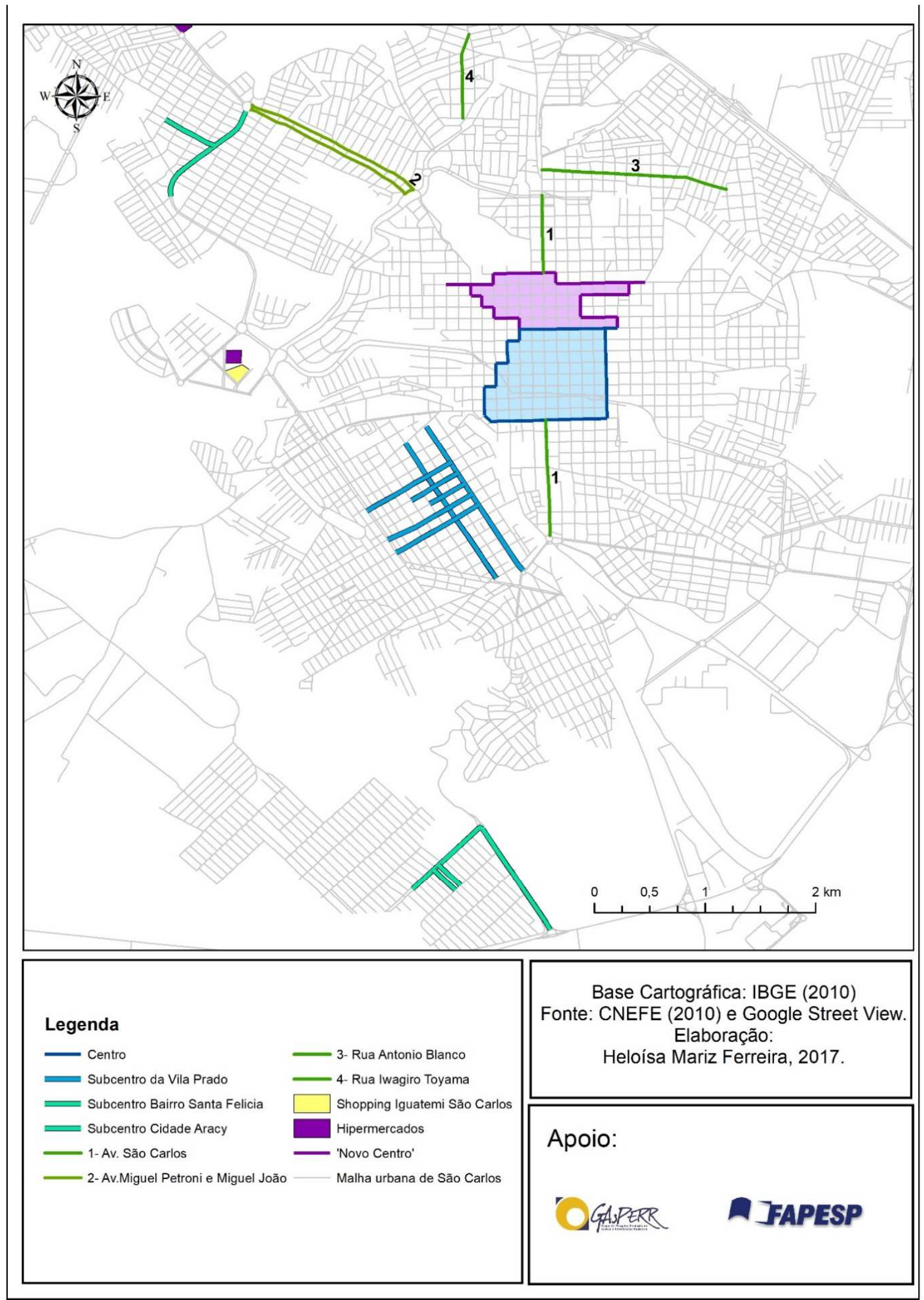

Figura 3 - São Carlos (SP). Áreas centrais, 2017. Extraído de Ferreira (2018) 
O surgimento de novas áreas centrais implica uma desconcentração espacial de atividades terciárias, uma vez que o centro da cidade não mais aglomera todo o comércio e serviços da cidade, mas a implantação de shopping centers e, em menor medida, de hipermercados promove também desconcentração espacial de filiais e franquias, estabelecimentos que atraem grande número de consumidores, como apreendemos da análise de entrevistas com citadinos das três cidades.

Com efeito, shopping centers e hipermercados implicam em mudanças na centralidade intraurbana. Isso porque redefinem, em razão da grande atração de consumidores, os fluxos, que anteriormente convergiam quase unilateralmente para o centro da cidade. Cabe destacar, todavia, que os hipermercados atraem citadinos de variados segmentos socioeconômicos, ao passo que os shopping centers, consumidores de médio a alto poder aquisitivo.

Em função das repercussões da implantação dessas grandes superfícies comerciais e de serviços, as relações entre áreas centrais em estruturas policêntricas são marcadas por relações de concorrência e complementaridade, de modo análogo ao observado nos âmbitos regional e metropolitano ${ }^{8}$. Temos por relações de concorrência aquelas que são características de proeminência de área central sobre outras, compondo, neste sentido, estrutura espacial hierárquica, como se mostram as mono e multicêntricas, e tendo como contraponto relações de subordinação das demais áreas centrais. As relações de complementaridade $^{9}$ correspondem, por sua vez, à ausência de predomínio de áreas, em estruturas não hierárquicas.

Decorrentes da introdução dessas novas relações, destacamos, entre as transformações no centro de Marília, Presidente Prudente e São Carlos, as seguintes: (i) o incremento da participação de lojas voltadas para o público de menor poder aquisitivo, em dinâmica concomitante a lógicas espaciais de grifes de instalação em novos espaços de consumo, notadamente shopping centers; (ii) declínio de práticas de consumo de frequentadores de médio e alto poder de compra, que exibem preferência por novos espaços de consumo,

\footnotetext{
${ }^{8}$ São exemplos de análises realizadas acerca do policentrismo em espaços metropolitanos e regionais, os de autoria de Aguilera e Mignot (2003), Bailey e Turok (2000), Gárcia-López e Muñiz-Oliveira (2007), Gonçalves (2016), Hall e Pain (2006), Kloosterman e Musterd (2001), Pessoa (2011), Riverte, Yserte e Águila (2010), Roca, Arellano e Moix (2011), Barata-Salgueiro (1997), Taylor, Evans e Pain (2006).

${ }^{9}$ Relações de complementaridade foram também analisadas por Camagni (1993), que se voltou à compreensão da escala da rede urbana, e Whitacker (1997, 2003), da intraurbana.
} 
inclusive hipermercados; (iii) perda de funções, a exemplo da oferta de artigos alimentícios e uso residencial de elevado status social; (iv) reformas e intervenções públicas, sobretudo em calçadões e praças, no intuito de fomento do consumo no centro; e (v) expansão territorial da área e, a partir disso, formação de novas áreas centrais, como eixos de desdobramento da área central Esmeraldas, em Marília, Washington Luiz, em Presidente Prudente, e o Novo centro, em São Carlos, representados cartograficamente nos mapas 1, 2 e 3 .

Entretanto, mesmo em estruturas espaciais complexas, marcadas por novas relações entre áreas centrais, o centro da cidade se mantém relevante, constituindo o que tratamos como condição preexistente, apoiando-nos em Santos (1996), quando adverte:

[...] as condições preexistentes em cada lugar, seu estoque de recursos, materiais ou não, e de organização - estas rugosidades - constituem as coordenadas que orientam as novas ações. Se consideramos o espaço tal como existe em dado momento, como uma realidade objetiva, e o tempo como as ações que nele se vão inserir, então é o tempo que depende do espaço e não o contrário (SANTOS, 1996, p. 203).

Nesse sentido, o policentrismo não resulta em estruturas espaciais totalmente novas, posto que se desenrola em contextos em que o centro da cidade se constituiu por meio de acúmulo de funções - econômicas, sociais, políticas e lúdicas -, que na segunda metade do século XX, apresentou expressivas redefinições, por consequência das repercussões da emergência de novas áreas centrais.

Considerando as mudanças na estrutura urbana e nas relações entre as áreas centrais, temos como hipótese que não há, necessariamente, coincidência territorial entre o centro principal e a área central primeiramente surgida, embora não descartamos a importância desta área, enquanto condição preexistente aos novos processos da centralidade intraurbana. Para averiguar tal hipótese, buscamos compreender as mudanças e permanências da centralidade intraurbana de Marília, Presidente Prudente e São Carlos, por meio da análise das lógicas espaciais de empresas e práticas espaciais de consumo de citadinos, para apreendermos, respetivamente, o que está localizado e os fluxos que convergem para as diferentes áreas centrais. 


\section{Novas relações entre áreas centrais e o centro principal}

Com privilégio às dimensões da troca e do consumo na compreensão da estrutura e centralidade intraurbanas, entendemos que o centro principal corresponde, entre transformações e permanências, à área central que exibe primazia entre lógicas espaciais e práticas espaciais de consumo, que identificamos, no presente artigo, a partir de pesquisa acerca das cidades médias de Marília, Presidente Prudente e São Carlos.

Realizamos a análise por meio de amplo conjunto de procedimentos metodológicos, valendo-nos, para apreensão do porte e da diversidade da concentração de atividades, da coleta de dados de uso do solo no CNEFE e posterior classificação conforme CNAE; da identificação, em realização de trabalhos de campo, de estabelecimentos franqueados e filiais, no intuito de conferirmos a complexidade do capital das empresas; e da análise de questionários e entrevistas realizadas por membros do Projeto Temático "Lógicas econômicas e práticas espaciais contemporâneas: cidades médias e consumo".

Nesse sentido, abarcamos componentes quantitativos, concernentes às concentrações absolutas de atividades, às aglomerações de franquias e filiais e à frequência de compras e, por outro lado, componentes qualitativos, ligados à diversidade de atividades desenvolvidas, às escalas de atuação das empresas de capital externo e menções, em descrições tecidas em entrevistas, de áreas centrais de realização de práticas de consumo.

$\mathrm{Na}$ tabela 1, referente à concentração e à diversidade de atividades econômicas desenvolvidas nas áreas centrais das três cidades, conferimos que o centro exibe significativa importância. 
Cidades

\begin{tabular}{|c|c|c|c|c|c|c|c|c|}
\hline \multicolumn{3}{|c|}{ Marília } & \multicolumn{3}{|c|}{ Presidente Prudente } & \multicolumn{3}{|c|}{ São Carlos } \\
\hline Centro & № $\mathrm{E}$. & № C. & Centro & № $\mathrm{E}$. & № C. & Centro & № $\mathrm{E}$. & № C. \\
\hline Centro & 1960 & 136 & Centro & 1517 & 117 & Centro & 993 & 107 \\
\hline & & & & & & 'Novo centro' & 630 & 90 \\
\hline Subcentros & № $\mathrm{E}$. & № C. & Subcentros & № $\mathrm{E}$. & № C. & Subcentros & № $\mathrm{E}$. & № C. \\
\hline Nova Marília & 511 & 71 & $\begin{array}{l}\text { Jardim } \\
\text { Bongiovani }\end{array}$ & 341 & 81 & Vila Prado & 592 & 89 \\
\hline $\begin{array}{l}\text { Santa } \\
\text { Antonieta }\end{array}$ & 192 & 64 & COHAB & 174 & 45 & Santa Felícia & 118 & 45 \\
\hline & & & Ana Jacinta & 347 & 65 & Cidade Aracy & 164 & 42 \\
\hline $\begin{array}{l}\text { Eixos de } \\
\text { desdobramento } \\
\text { da área central }\end{array}$ & № $\mathrm{E}$. & № C. & $\begin{array}{l}\text { Eixos de } \\
\text { desdobramento } \\
\text { da área central }\end{array}$ & № $\mathrm{E}$. & № C. & $\begin{array}{l}\text { Eixos de } \\
\text { desdobramento } \\
\text { da área central }\end{array}$ & № $E$. & № C. \\
\hline Rio Branco & 75 & 26 & $\begin{array}{l}\text { Coronel José } \\
\text { Soares } \\
\text { Marcondes }\end{array}$ & 103 & 37 & São Carlos & 153 & 45 \\
\hline $\begin{array}{l}\text { Coronel } \\
\text { Galdino de } \\
\text { Almeida }\end{array}$ & 45 & 13 & $\begin{array}{l}\text { Washington } \\
\text { Luiz }\end{array}$ & 142 & 49 & & & \\
\hline $\begin{array}{l}\text { Das } \\
\text { Esmeraldas }\end{array}$ & 49 & 19 & Brasil & 175 & 37 & & & \\
\hline Eixos & № $\mathrm{E}$. & № C. & Eixos & № E. & № C. & Eixos & № $\mathrm{E}$. & № C. \\
\hline Tiradentes & 36 & 19 & Coronel Albino & 110 & 40 & \begin{tabular}{|l} 
Iwagiro \\
oyama
\end{tabular} & 62 & 24 \\
\hline $\begin{array}{l}\text { Vicente } \\
\text { Ferreira }\end{array}$ & 73 & 31 & $\begin{array}{l}11 \text { de Maio e } \\
14 \text { de } \\
\text { Setembro }\end{array}$ & 117 & 40 & $\begin{array}{l}\text { Miguel Petroni } \\
\text { e Miguel João }\end{array}$ & 110 & 45 \\
\hline $\begin{array}{l}\text { B. Eduardo } \\
\text { Gomes }\end{array}$ & 32 & 20 & $\begin{array}{l}\text { São Paulo e } \\
\text { Antônio } \\
\text { Rodrigues }\end{array}$ & 78 & 26 & \begin{tabular}{|l} 
Antônio \\
Blanco
\end{tabular} & 76 & 31 \\
\hline República & 168 & 57 & & & & & & \\
\hline $\begin{array}{ll}\text { Pedro de } \\
\text { Toledo }\end{array}$ & 111 & 44 & & & & & & \\
\hline $\begin{array}{l}\text { Shopping } \\
\text { centers }\end{array}$ & № $\mathrm{E}$. & № C. & $\begin{array}{l}\text { Shopping } \\
\text { centers }\end{array}$ & № $\mathrm{E}$. & № C. & $\begin{array}{l}\text { Shopping } \\
\text { centers }\end{array}$ & № $\mathrm{E}$. & № C. \\
\hline $\begin{array}{l}\text { Marília } \\
\text { Shopping }\end{array}$ & 124 & 25 & Prudenshopping & 143 & 24 & $\begin{array}{l}\text { Shopping } \\
\text { Iguatemi }\end{array}$ & 110 & 25 \\
\hline $\begin{array}{l}\text { Esmeralda } \\
\text { Shopping }\end{array}$ & 46 & 12 & $\begin{array}{l}\text { Parque } \\
\text { Shopping } \\
\text { Prudente }\end{array}$ & 63 & 22 & & & \\
\hline
\end{tabular}

Tabela 1: Número de estabelecimentos e de classes de atividades das áreas centrais em Marília, Presidente Prudente e São Carlos.

Fonte de dados: CNEFE (2010), CNAE 2.0 (2010), sítio eletrônico dos shopping centers Marília Shopping, Esmeralda Shopping, Prudenshopping, Parque Shopping Prudente e Shopping Iguatemi São Carlos. Legenda: № E.: Número de estabelecimentos e № C.: Número de classes de atividades.

Extraído de Ferreira (2018). 
Tratando, inicialmente, do porte da concentração espacial de atividades, verificamos que o centro das três cidades que pesquisamos conta com grande número de estabelecimentos. Em Marília, identificamos 1960 unidades, em Presidente Prudente, 1517, e, em São Carlos, 993, seguidos pelos subcentros Nova Marília, em Marília, Ana Jacinta, em Presidente Prudente, e Vila Prado, em São Carlos, que exibem 511, 347 e 592 estabelecimentos, respetivamente.

Em São Carlos, além do centro e subcentros, destacamos o que tratamos como Novo centro, que concentra 630 estabelecimentos, em inferioridade menos acentuada ao centro da cidade. Já eixos de comércio e serviços ausentes de especialização, eixos de desdobramento da área central e shopping centers não alcançam 200 estabelecimentos.

No que se refere, portanto, ao porte da concentração espacial de atividades, o centro ostenta, especialmente em Marília e Presidente Prudente, posição superior em hierarquia quantitativa, com atração de grande número de estabelecimentos, sem equivalência por outras áreas centrais.

A elevada concentração espacial de atividades correspondeu à importante característica do centro da cidade, como podemos observar nas descrições de Johnson (1974), quando analisou essa área central em países desenvolvidos, no século XX. Nossa análise de Marília, Presidente Prudente e São Carlos indica a permanência desse atributo no centro de cidades de estruturação mais complexa, no século XXI. Isso favorece a continuidade do centro primeiramente surgido enquanto centro principal, ao revelar grande capacidade de atração de escolhas locacionais de empresas do setor varejista, a despeito da formação de novas áreas centrais.

Quanto à diversidade de atividades, o centro apresenta também superioridade. Em Marília, esta área central conta com 136 classes de atividades do CNAE, em Presidente Prudente, 117, e, em São Carlos, 107. No centro dessas cidades, conferimos gama variada tanto de serviços como de comércio, sendo os de participação relativa mais expressiva a comercialização de artigos do vestuário, calçado, móveis, medicamentos e prestação de serviços de alimentação, médicos, odontológicos, advocatícios, contábeis, de beleza e bancários, além de pequenas unidades industriais, a exemplo de gráficas e confecções de roupas. 
O Novo centro, em São Carlos, apresenta 90 classes e os subcentros exibem, especialmente o do Nova Marília, o do Jardim Bongiovani e o da Vila Prado, número semelhante de classes, sendo, respectivamente, 71, 81 e 89. Eixos de desdobramento da área central e shopping centers exibem números bastante inferiores de classes de atividades, em indicativo de especialização funcional de tais espaços de consumo, consistindo nos casos mais ilustrativos o Esmeralda Shopping, em Marília, com 12 classes de atividades, e o Parque Shopping Prudente, com 22 classes.

Nesse sentido, quanto à diversidade de atividades econômicas, o centro da cidade, sobretudo em Marília, o Novo centro, no caso de São Carlos e, em menor medida, os subcentros, apresentam superioridade, oferecendo aos consumidores ampla oferta de bens e serviços, em importante atributo, que os distinguem de outras áreas centrais, constituídas de dinâmicas de especialização funcional.

Ainda no que se refere ao esforço de compreensão de lógicas espaciais, é premente, a nosso ver, a análise da complexidade do capital das diferentes áreas centrais das três cidades, uma vez que nos permite apreender escolhas locacionais de grandes grupos varejistas, presentes em cidades médias a partir, sobretudo, de filiais e franquias, articulando tais cidades e suas diferentes áreas centrais ao "funcionamento global da sociedade e da economia", em verticalidades, como apontou Santos (1994c), ao analisar a atuação de agentes hegemônicos da economia.

A compreensão da complexidade do capital se mostra igualmente fundamental pela expressiva atração de consumidores exercida por unidades comerciais e de serviços ligadas a capitais externos, como verificamos em menções dos principais estabelecimentos visitados nos diferentes espaços de consumo, por meio da análise de questionários e entrevistas.

$\mathrm{Na}$ análise da complexidade do capital das empresas situadas em áreas centrais das três cidades que pesquisamos, verificamos que as maiores concentrações de franquias e filiais, inclusive de grandes lojas de departamentos, correspondem às do centro da cidade e dos shopping centers mais importantes.

Em Marília e São Carlos, o centro conta maior número dessa tipologia de estabelecimentos, com a presença de grandes filiais como Renner, Riachuelo e Marisa, ao passo que em 
Presidente Prudente, tais lojas estão situadas no mais importante shopping center, o Prudenshopping, e o centro apresenta participação mais expressiva de lojas de empresas de atuação nacional e regional.

Ainda que, em São Carlos, o Shopping Iguatemi apresente elevada aglomeração de franquias, conferimos presença também considerável desta tipologia de estabelecimentos, inclusive daquelas vinculadas a empresas de atuação nacional, no Novo centro e no centro da cidade.

Eixos de desdobramento da área central contam com algumas filiais e, notadamente, franquias, como são ilustrativos a Avenida das Esmeraldas, em Marília, a Avenida Washington Luiz, em Presidente Prudente, e Avenida São Carlos, em São Carlos, nas quais conferimos franquias, especialmente, de lanchonetes fast food e grifes de roupas. Subcentros exibem, por outro lado, números pouco relevantes.

Além das díspares concentrações de franquias e filiais, conferimos padrões locacionais distintos entre os modos de organização e entre as atividades desempenhadas pelas unidades de comércio ou serviços. No que diz respeito ao primeiro padrão locacional, destacamos tendência expressiva de concentração espacial de filiais, especialmente de empresas de escalas regional e nacional de atuação, no centro das três cidades, ao passo que franquias, de grupos de escalas nacional e internacional, encontram-se aglomeradas, em grande medida, em shopping centers e eixos de desdobramento da área central.

É exceção, entretanto, à tendência geral que fizemos alusão a localização no centro de franquias de empresas de escala nacional de atuação, que apresentam elevada desconcentração espacial, não somente a partir da instalação em grande número de centros urbanos, no âmbito da rede urbana, como também em várias das áreas centrais, na dimensão intraurbana, como constituem os casos do O Boticário, Hering, Cacau Show e Chiquinho Sorvetes.

Quanto às distinções de concentrações de franquias e filiais conforme os ramos de comércio e serviços, verificamos tendências de maiores aglomerações do comércio de alimentos em hipermercados, de vestuário e calçados em shopping centers e no centro da cidade e serviços de alimentação desempenhados quase exclusivamente em shopping centers e de bancos e financeiras, no centro. 
No que diz respeito, então, à complexidade do capital das empresas, sintetizamos que, de modo dessemelhante ao porte e à diversidade da concentração espacial de atividades, os novos espaços de consumo exibem elevada aglomeração de franquias e filiais, notadamente de empresas de atuação nacional e internacional, estabelecendo, no caso dos shopping centers, números equivalentes ao centro, como no caso do Marília Shopping e Iguatemi São Carlos, ou superioridade ao centro, a exemplo do exercido pelo Prudenshopping, em Presidente Prudente.

Quanto às práticas espaciais de consumo, destacamos redefinições observadas na produção do espaço urbano que se mostram atinentes a alterações dos fluxos, com a emergência de várias áreas centrais, como subcentros, e à instrumentalização de alguns dos espaços de consumo para distinção social, especialmente eixos de desdobramento da área central e shopping centers, como advertiu Sposito (1991), em associação aos processos de segmentação socioespacial.

Embora, na análise de entrevistas com citadinos das três cidades, não tenhamos identificado referências explícitas às escolhas a partir de tal motivação, chamamos atenção para padrões contrários de práticas espaciais de consumo de indivíduos de maiores rendimentos, em comparação aos de rendas inferiores.

Isso porque, conferimos que consumidores de média a baixa renda realizam suas práticas de consumo, sobretudo, no centro da cidade, com diversas menções, em entrevistas e questionários, a lojas reconhecidamente populares, como os estabelecimentos Torra Torra e Patibum. Ainda que citadinos de rendimentos mais elevados tenham também feito referências às compras no centro, suas práticas se dão, em comparação aos demais segmentos socioeconômicos, em shopping centers, sobretudo o Marília Shopping, Prudenshopping e Iguatemi São Carlos.

Enquanto exceções a esses padrões, identificamos o consumo em shopping centers por indivíduos de menores rendimentos, especialmente os mais jovens, e no centro da cidade pelos de maior poder aquisitivo, sobretudo aqueles que residem próximo a esta área central e que exibem preferências a lojas tradicionais do centro.

De modo distinto, não configurando segmentação socioespacial, os hipermercados são utilizados, como podemos verificar na figura 4, pela quase totalidade de citadinos, para o 
consumo de artigos alimentícios, inclusive para citadinos de menores rendimentos, que relataram idas frequentes, em alguns casos semanais, em busca de promoções e comparações entre preços praticados em diversas dessas áreas centrais.

Com efeito, os hipermercados manifestam significativa centralidade, atraindo consumidores do conjunto da cidade, pertencentes a diferentes segmentos socioeconômicos, que os utilizam, em sua grande maioria, para compras de artigos alimentícios. Em Marília e Presidente Prudente, as práticas de consumo destes bens em hipermercados, em associação a alguns dos supermercados, alcançam porcentagens próximas a $100 \%$ e, em São Carlos, $90 \%$.

Tais práticas espaciais implicam, com efeito, uma redefinição significativa da centralidade intraurbana, uma vez que hipermercados, situados fora do centro, e, em menor medida, supermercados, alteram, de modo intenso, fluxos de consumidores, tecendo, com isso, relações de concorrência ao centro da cidade.

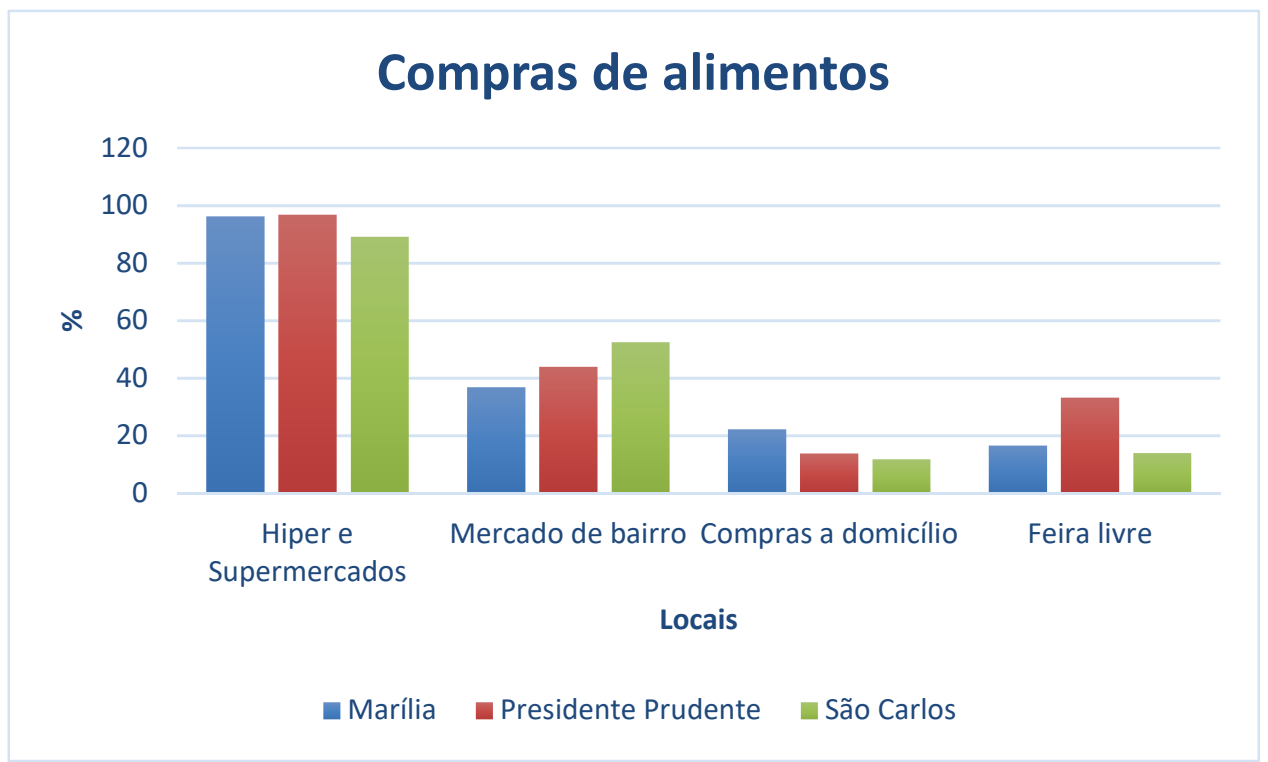

Figura 4: Áreas centrais para compras de alimentos em Marília, Presidente Prudente e São Carlos (SP). Fonte: Questionários disponibilizados na Plataforma de Gerenciamento de Informações do Projeto Temático 'Lógicas econômicas e práticas espaciais contemporâneas: cidades médias e consumo'. Extraído de Ferreira (2018).

Tal redefinição se mostra ainda mais expressiva se consideramos a frequência das práticas de consumo de alimentos em hipermercados e supermercados, sendo predominantes idas "Uma vez por semana", com cerca de 50\%, em Marília, 40\%, em Presidente Prudente, e 30\%, em São Carlos. 


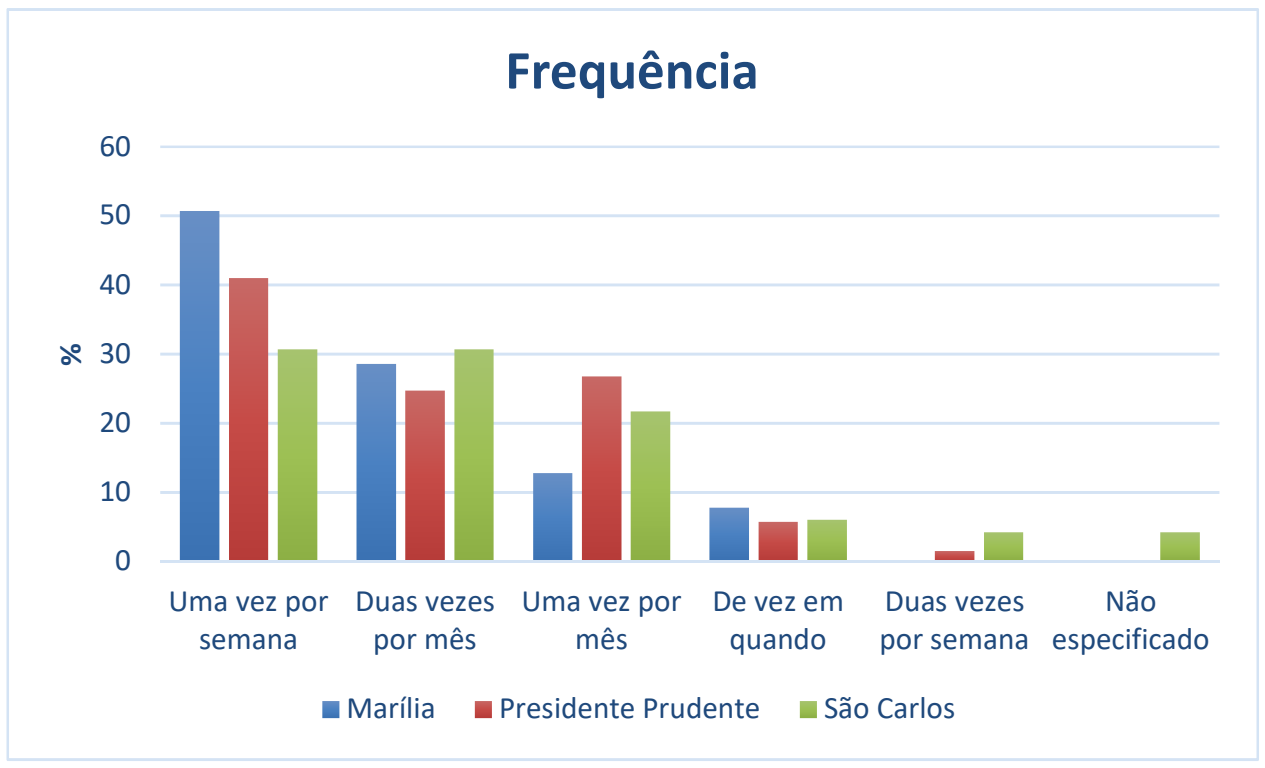

Figura 5: Frequência das compras de alimentos em hiper e supermercados Marília, Presidente Prudente e São Carlos (SP).

Fonte: Questionários disponibilizados na Plataforma de Gerenciamento de Informações do Projeto Temático 'Lógicas econômicas e práticas espaciais contemporâneas: cidades médias e consumo'.

Extraído de Ferreira (2018).

As práticas de consumo relativas às compras de alimentos são também realizadas, como exposto na figura 4, em porcentagens substancialmente inferiores, em mercados de bairro, feiras livres e outros estabelecimentos situados, notadamente, em subcentros, a exemplo de pequenos mercados, padarias e açougues.

Já para as práticas de consumo de artigos do vestuário e calçados, verificamos, na figura 6, a realização, predominante, no centro das três cidades e em shopping centers, especialmente no Marília Shopping, em Marília, e no Prudenshopping, sendo que, como já assinalamos, a cidade de São Carlos conta apenas um destes espaços de consumo.

Na figura 6, visualizamos que em São Carlos, aproximadamente $90 \%$ dos citadinos realizam tais práticas no centro, em Presidente Prudente, $80 \%$, e em Marília, 70\%, um indicativo de grande importância dessas áreas centrais. No que se refere às práticas tecidas em shopping centers, em Marília e Presidente Prudente, cerca de $60 \%$ os utilizam em suas compras, ao passo que em São Carlos, em centralidade menos expressiva do Shopping Iguatemi, menos de $40 \%$ seleciona shopping centers para compras de roupas e calçados. 
Em participações inferiores, para aproximadamente 10 a $20 \%$ dos consumidores, tais práticas também se dão em hipermercados; camelódromos; lojas de bairro, situadas, especialmente, em subcentros; e por meio de compras a domicílio.

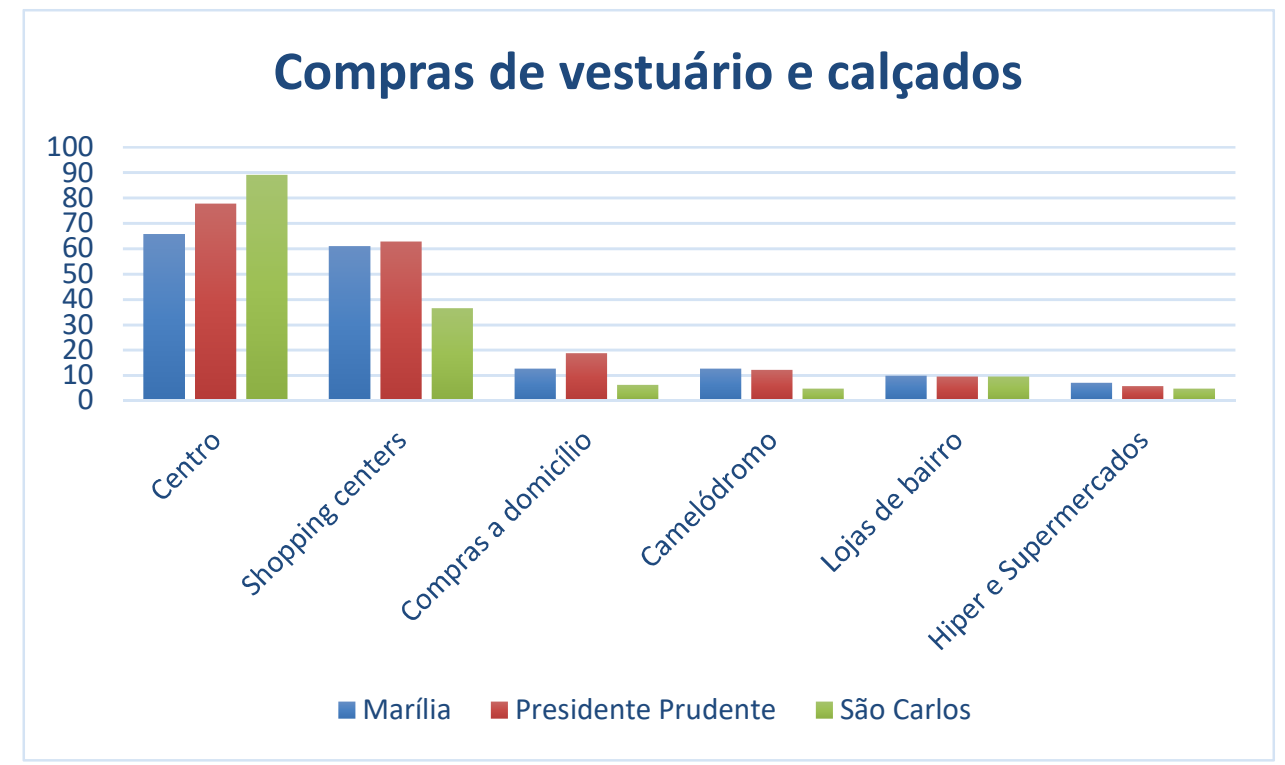

Figura 6: Áreas centrais para compras de vestuário e calçados em Marília, Presidente Prudente e São Carlos (SP).

Fonte: Questionários disponibilizados na Plataforma de Gerenciamento de Informações do Projeto Temático 'Lógicas econômicas e práticas espaciais contemporâneas: cidades médias e consumo'.

Extraído de Ferreira (2018).

Embora o centro das três cidades seja o espaço preferencial para a realização de práticas de consumo de artigos do vestuário e calçados, a frequência se mostra, como visualizamos na figura 7, menos recorrente que a anterior, de aquisição de alimentos, com menções majoritárias à ida "De vez em quando", por 60 a 70\% dos citadinos, e "Uma vez por mês", para cerca de $20 \%$. Com efeito, no cotidiano das práticas espaciais de consumo, a ida ao centro exibe menor importância, se comparado aos hipermercados.

No que diz respeito aos shopping centers, porcentagens similares relativas às práticas realizadas "De vez em quando" foram identificadas, como é possível conferir na figura 8, com menores participações de menções "Uma vez por mês", com aproximadamente $10 \%$. 


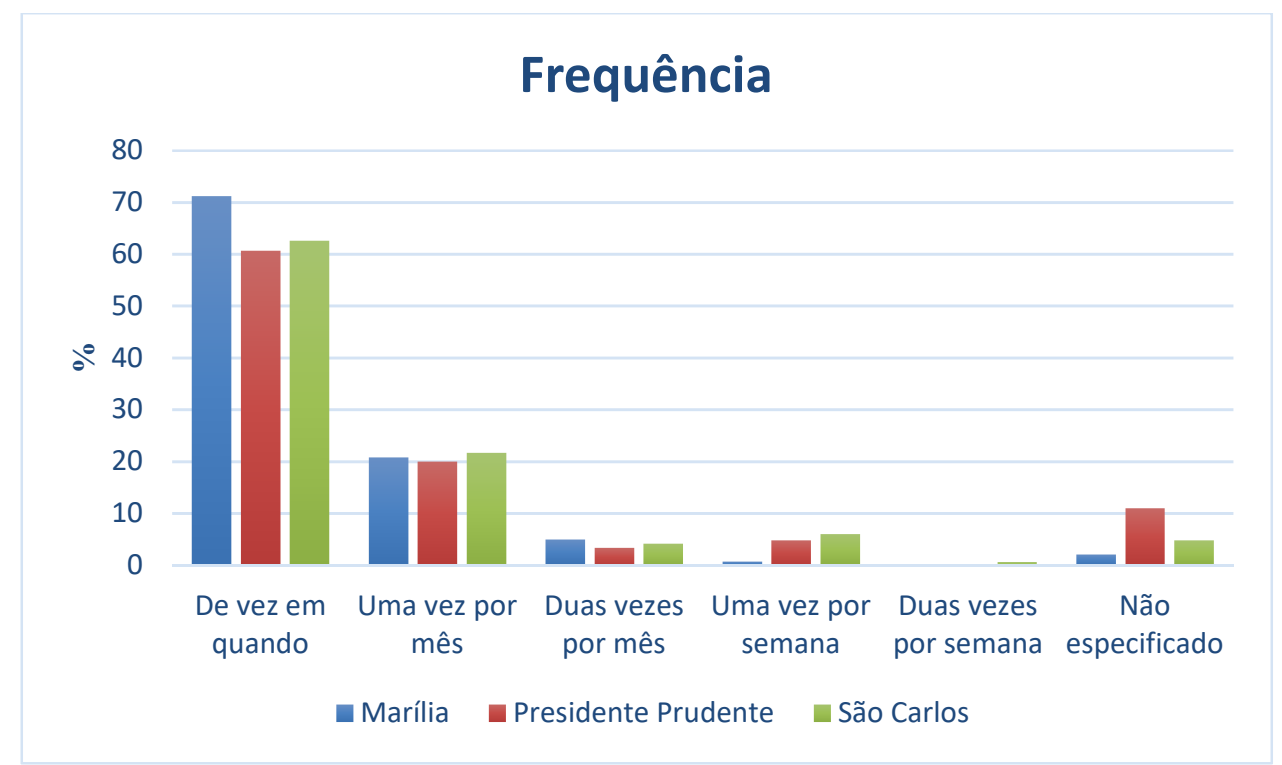

Figura 7: Frequência de compras de vestuário e calçados no centro de Marília, Presidente Prudente e São Carlos (SP).

Fonte: Questionários disponibilizados na Plataforma de Gerenciamento de Informações do Projeto Temático 'Lógicas econômicas e práticas espaciais contemporâneas: cidades médias e consumo'.

Extraído de Ferreira (2018).

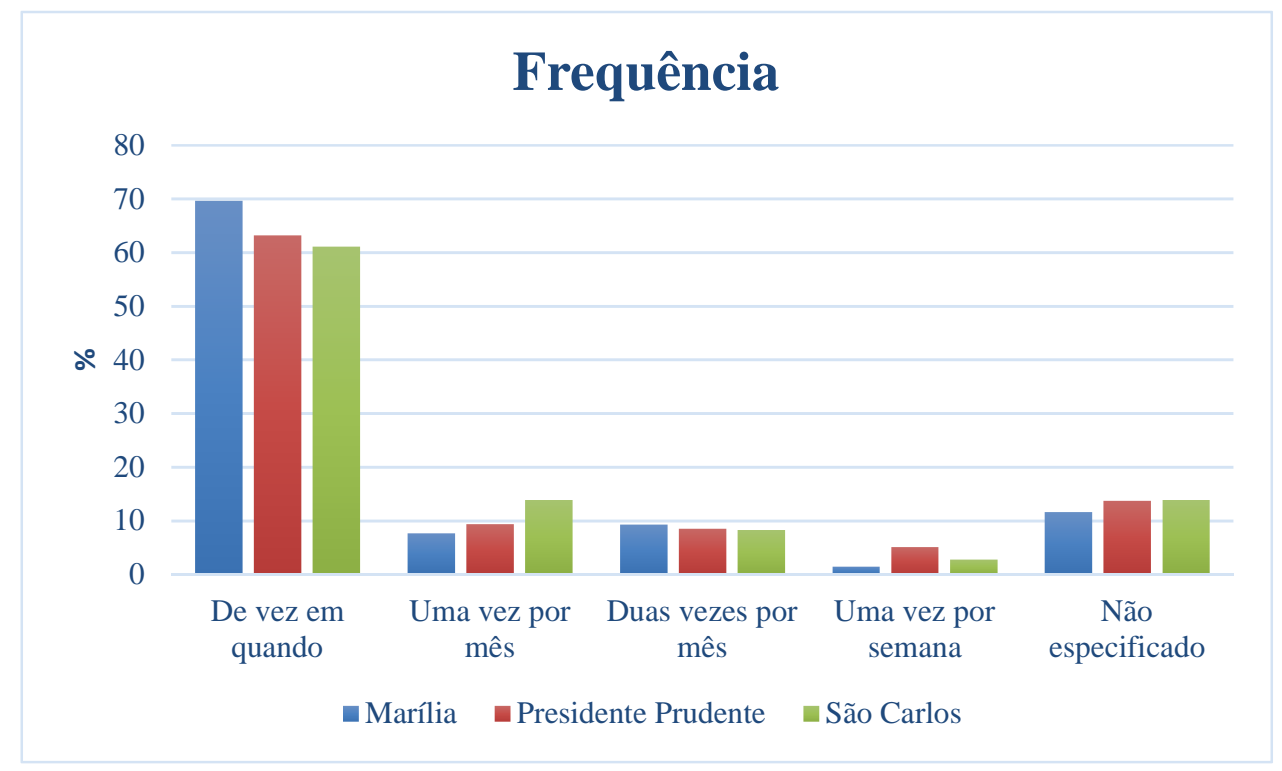

Figura 8: Frequência de compras de vestuário e calçados em shopping centers de Marília, Presidente Prudente e São Carlos (SP).

Fonte: Questionários disponibilizados na Plataforma de Gerenciamento de Informações do Projeto Temático 'Lógicas econômicas e práticas espaciais contemporâneas: cidades médias e consumo'. Extraído de Ferreira (2018).

No que se refere às práticas de consumo de eletroeletrônicos, conferimos na figura 9 significativa importância do centro, utilizado, em Marília e Presidente Prudente, por cerca 
de $60 \%$ dos citadinos e, em São Carlos, por quase 90\%. Em São Carlos, também identificamos maior porcentagem, aproximadamente $40 \%$, de citadinos que consomem esses bens em shopping center, enquanto em Marília e Presidente Prudente, tais práticas de consumo são tecidas por 10 a 30\%, tendo maior participação, nestas duas cidades, as compras a domicílio, mencionadas por cerca de $30 \%$.

Os citadinos relataram, entre as lojas em que consomem tais artigos, as compras em estabelecimentos de grandes grupos varejistas, de que são ilustrativos Casas Bahia, Magazine Luiza e Ponto Frio, que concedem empréstimos e cartões próprios, propiciando o consumo de indivíduos de camadas de menores rendimentos e consistindo um atrativo para citadinos de elevado poder aquisitivo, que também se valem de parcelamentos para a aquisição de eletroeletrônicos, de maior valor unitário, como apreendemos da análise das entrevistas.

Todavia, como podemos observar na figura 10, a frequência de práticas de consumo de eletroeletrônicos é ainda menos recorrente, em comparação às compras de artigos do vestuário e calçados e de alimentos, em preponderante consumo "De vez em quando", para cerca de 80 a $100 \%$ dos citadinos, o que se mostra indicativo de inferior relevância nas escolhas cotidianas de áreas centrais pelos citadinos.

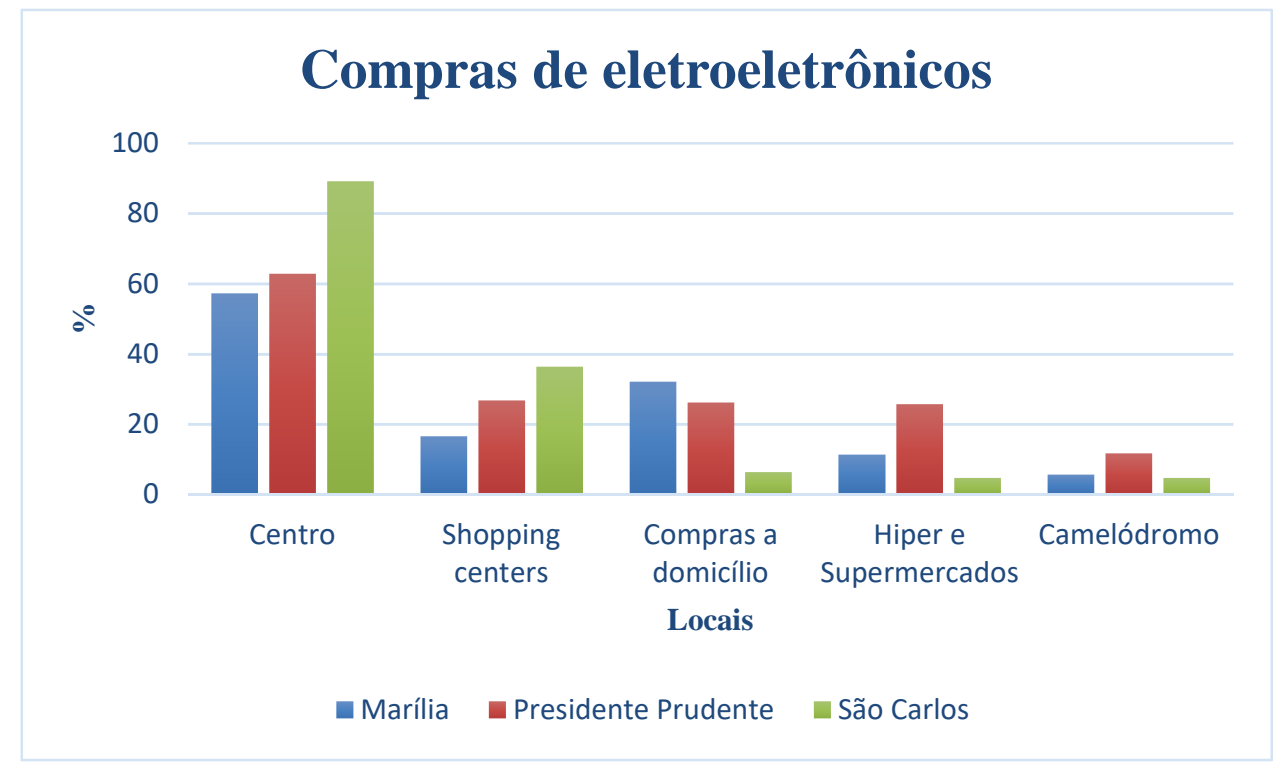

Figura 9: Áreas centrais para compras de eletroeletrônicos em Marília, Presidente Prudente e São Carlos (SP). Fonte: Questionários disponibilizados na Plataforma de Gerenciamento de Informações do Projeto Temático 'Lógicas econômicas e práticas espaciais contemporâneas: cidades médias e consumo'.

Extraído de Ferreira (2018). 


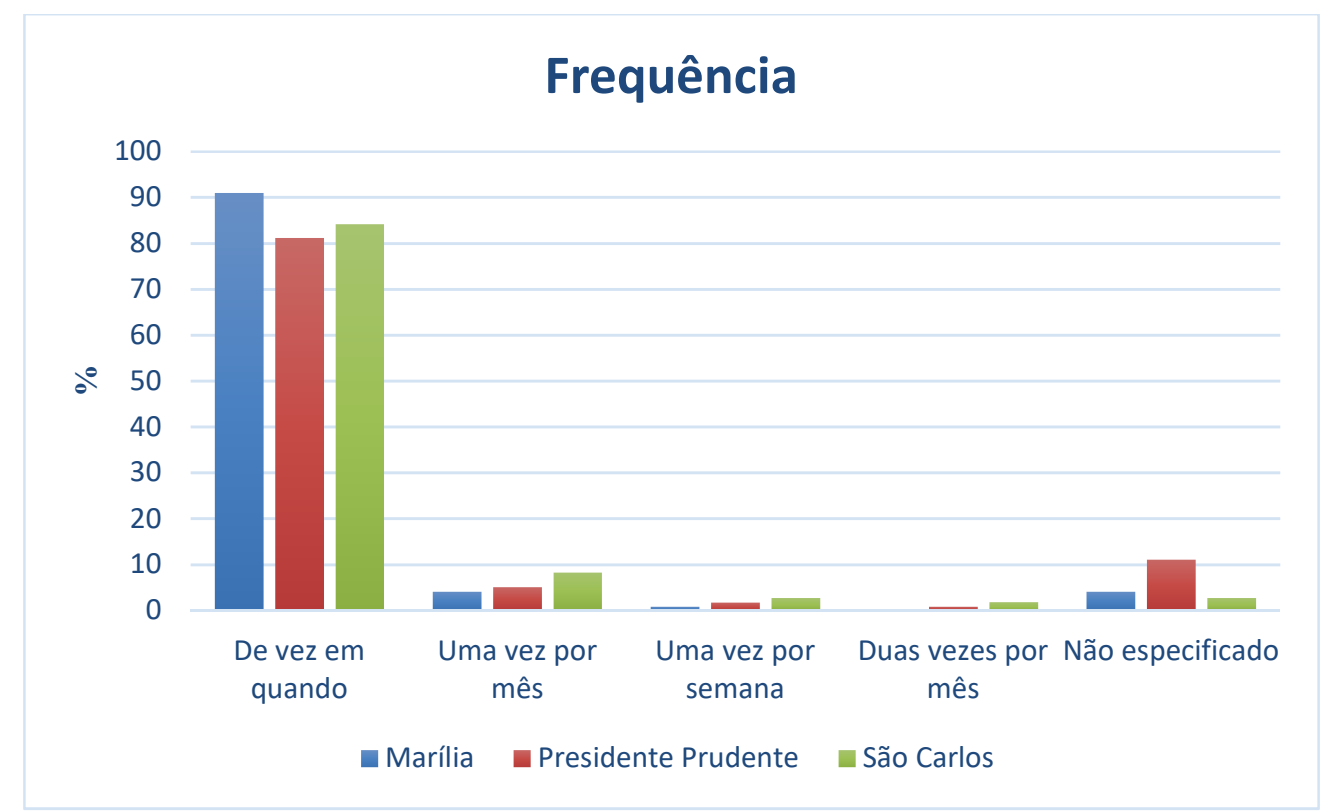

Figura 10: Frequência de compras de eletroeletrônicos no centro em Marília, Presidente Prudente e São Carlos (SP).

Fonte: Questionários disponibilizados na Plataforma de Gerenciamento de Informações do Projeto Temático 'Lógicas econômicas e práticas espaciais contemporâneas: cidades médias e consumo'.

Extraído de Ferreira (2018).

A análise das práticas espaciais de consumo é indicativa de uma redefinição das escolhas por áreas centrais, em comparação ao observado em estruturas mono e multicêntricas, nas quais a quase totalidade dos fluxos convergiam ao centro da cidade. Tal mudança se deve à implantação de novos espaços de consumo, especialmente shopping centers, e hipermercados, que exibem grande atração de consumidores e capacidade, com isso, de complexificação da centralidade intraurbana.

Entretanto, considerando as práticas espaciais de consumo de alimentos, realizadas em hipermercados; vestuário e calçados, tecidas, especialmente, no centro e em shopping centers; e eletroeletrônicos, no centro, conferimos, a despeito das complexas relações de concorrência e complementaridade tecidas por shopping centers e hipermercados, superioridade do centro, especialmente em São Carlos e Marília e, em menor medida, em Presidente Prudente.

Podemos, então, com base em Certeau (1998), afirmar que a compreensão das dinâmicas sociais e espaciais não pode se restringir aos impactos de ações de agentes hegemônicos e externos, a exemplo dos grandes grupos varejistas, pois devem levar em conta permanências em práticas espaciais de consumo, a partir da análise de escolhas de citadinos, no tempo cotidiano. 
Associando essa conclusão, no que diz respeito às práticas espaciais de citadinos, às obtidas através da compreensão das lógicas espaciais das empresas, com identificação do porte e da diversidade da concentração espacial de atividades e complexidade do capital das empresas, apontamos que em Marília e São Carlos, o centro principal coincide com a área central primeiramente surgida, com predomínio de relações de subordinação ao centro, ao passo que em Presidente Prudente, a identificação de um centro principal se mostra frágil, em função das relações de complementaridade e, por vezes, da concorrência estabelecidas, sobretudo, pelo Prudenshopping.

Salientamos, por fim, que a complexificação da identificação do centro principal em estruturas policêntricas deve considerar o caráter dialético dos processos atinentes ao centro e à centralidade intraurbana. Isso porque tais processos culminam na combinação de transformações, como a desconcentração espacial de atividades, e permanências, a exemplo da continuidade da aglomeração de comércio e serviços no centro, em concomitante perda de importância e reforço da centralidade do centro.

\section{Conclusões}

Considerando importantes contribuições de Milton Santos (1985, 1994a, 1994b, 1994c, 1996), realizamos a análise do centro principal de Marília, Presidente Prudente e São Carlos,

subsumida à compreensão da estrutura policêntrica enquanto coexistência de áreas centrais, pertencentes a uma totalidade, apesar dos distintos períodos de formação no eixo das sucessões.

Em expressiva articulação de áreas centrais, o policentrismo é característico de relações de complementaridade e concorrência tecidas por novos espaços de consumo ao centro, mais complexas que a estrita subordinação a este espaço observada em estruturas mono e multicêntricas, permitindo-nos confirmar a hipótese da não mais imanente coincidência territorial entre o centro da cidade e o centro principal, levando em conta, todavia, a condição preexistente exercida pelo primeiro. 
Se, em Marília e São Carlos, conferimos coincidência territorial, em Presidente Prudente, atrelado aos maiores papéis desempenhados na rede urbana, verificamos maior complexidade das relações entre áreas centrais, com concorrência e complementaridade estabelecida por um dos shopping centers, o Prudenshopping, e superior número de hipermercados, que tecem relações de concorrência ao centro.

Não obstante as dessemelhanças entre as três cidades médias, ressaltamos similaridades quanto à complexificação da estrutura e centralidade intraurbanas, atinentes a novas lógicas e práticas espaciais, que promovem relações de complementaridade e concorrência, que se defrontam, dialeticamente, a condições preexistentes, com permanência de importantes funções e atração de consumidores no centro, confirmando, com isso, o necessário debate acerca do centro principal em estruturas policêntricas.

\section{Referências bibliográficas}

AGUILERA, M.; MIGNOT, D. Polycentrism et mobilite domicilie travail. In: XXXIXème Colloque de l'ASRDLF Concentration et ségrégation, dynamiques et inscriptions territoriales, Lyon, 2013, p. 1-15.

BAILEY, N.; TUROK, I.; Central Scotland as a Polycentric Urban Region: Useful Planning Concept or Chimera? Urban Studies, v. 38, n. 4, 2001, p. 697-715.

BARATA-SALGUEIRO, T. Lisboa, metrópole policêntrica e fragmentada. Finisterra, XXXII, 63, 1997, p. 179-190.

BAUDRILLARD, J. A sociedade de consumo. Lisboa: Edições 70, 1991. ISBN: 972441521X

BERRY, B. Shopping Centers and The Geography of Urban Areas. A Theoretical and Empirical Study of the Spatial Structure of Intraurban Retail and Service Business. 1958. 185 f. Tese (Doctor of Philosofy) - University of Washington, Seattle, 1958.

CAMAGNI, R. Organisation économique et réseux de villes. In: SALLEZ, A. (Dir.) Les villes, lieux d'Europe. Paris: Éditours de l"Aube, 1993, p.107- 28.

CERTEAU, M. de. A invenção do cotidiano. Artes de fazer. 3. ed. Petrópolis: Editora Vozes, 1998. ISBN: 8532611486 .

CORRÊA, R. L. O espaço urbano. São Paulo: Ática, 1989. ISBN: 9788508032600

DUARTE, H. da S. B. A cidade do Rio de Janeiro: descentralização das atividades terciárias. Os centros funcionais. Revista Brasileira de Geografia, 36 (1), 1974, p.53-98.

FERREIRA, H. M. O centro preexistente e o centro principal nas cidades policêntricas: transformações e permanências em Marília, Presidente Prudente e São Carlos-SP. 2018. 448 f. Tese (Doutorado em Geografia) Faculdade de Ciências e Tecnologia, Universidade Estadual Paulista, Presidente Prudente, 2018.

GARCÍA-LÓPEZ, M. A.; OLIVEIRA, I. M. Policentrismo o dispersión? Una aproximación desde la nueva economía urbana. Investigaciones regionales, n. 11, 2007, p. 25-43. 
GOMES, V. B. As atividades das grandes empresas do ramo supermercadista e a rede urbana brasileira no período recente. 2017. 507 f. Dissertação (Mestrado em Geografia) - Faculdade de Ciências e Tecnologia, Universidade Estadual Paulista, Presidente Prudente, 2017.

GONÇALVES, C. Hierarquia, policentrismo e complexidade em sistemas urbanos. E-metropolis, n. 25, ano 7, 2016, p. 26-34.

HALL, P.; PAIN, K. Firms and places: inside the Mega-City regions. In: (Org.). The polycentric metropolis: learning from mega-city regions in Europe. Londres: Earthscan, 2006, p. 91-103.

KLOOSTERMAN, R. C.; MUSTERD, S. The polycentric urban region: towards a research agenda. Urban Studies, v. 38, n. 4, 2001, p. 623-633.

LEFEBVRE, H. The production of space. Malden: MA, 1991. ISBN: 0631181776

LEFEBVRE, H. A revolução urbana. Belo Horizonte: UFMG, 1999. ISBN: 8570411952

LENCIONI, S. Concentração e centralização das atividades urbanas: uma perspectiva multiescalar. Reflexões a partir do caso de São Paulo. Revista de Geografia Norte Grande, 39, 2008, p. 7-20.

MELAZZO, E. S. Marília: especialização industrial e diversificação do consumo. Trajetórias de uma cidade média. In: SPOSITO, M. E. B.; ELIAS, D.; SOARES, B. R. (Org.). Agentes econômicos e reestruturação urbana e regional: Chillán e Marília. São Paulo: Outras expressões, 2012, p. 161 - 282.

MONTENEGRO, M. R. Novas apropriações do urbano e redefinições do consumo na metrópole de São Paulo. In: VI Congreso Iberoamericano de Estudios Territoriales y Ambientales, 2014, São Paulo. VI Congreso Iberoamericano de Estudios Territoriales y Ambientales, 2014. v. 1. p. 700-714.

PESSOA, R. P. P. Em busca de uma definição de policentrismo urbano para as metrópoles brasileiras. Revista Paranaense de Desenvolvimento, Curitiba, n. 120, 2011, p. 297-318.

PINTAUDI, S. M. Templo da mercadoria. Estudo sobre os shopping centers do estado de São Paulo. 156 f. 1989. Tese (Doutorado em Geografia) - Universidade de São Paulo, 1989.

ROCA, J.; ARELLANO, B.; MOIX, M. Estructura urbana, policentrismo y sprawl: los ejemplos de Madrid e Barcelona. Ciudad y territorio: Estudios territoriales, n. 168, 2011, p. 299-321.

SANTOS, M. Espaço e método. São Paulo: Hucitec, 1985. ISBN: 8531410851

SANTOS, M. Metamorfoses do espaço habitado. Fundamentos teóricos e metodológicos da Geografia. São Paulo: Hucitec, 1994a. ISBN: 8531410444

SANTOS, M. Por uma Economia Política da Cidade. São Paulo: Hucitec, 1994b. ISBN: 8531411203

SANTOS, M. Técnica, Espaço, Tempo. Globalização e Meio Técnico-científico-informacional. São Paulo: Hucitec, 1994c. ISBN: 8531410495

SANTOS, M. A natureza do espaço: técnica e tempo, razão e emoção. São Paulo: Hucitec, 1996. ISBN: 8531407133

SCIRÉ, C. D. de O. Financeirização da pobreza: crédito e endividamento no âmbito das práticas populares de consumo. Teoria \& Pesquisa, v. 20, 2011, p. 65-78.

SILVA, C. H. C. O papel dos supermercados e hipermercados nas relações entre cidade, comércio e consumo. Geografia (Rio Claro), Rio Claro, v. 30, n.3, 2005, p. 610-625.

SPOSITO, M.E.B. O centro e as formas de expressão da centralidade urbana. Revista de Geografia. São Paulo: UNESP, n.10, 1991, p. 1-18.

SPOSITO, M.E.B. As cidades médias e os contextos econômicos contemporâneos. In: SPOSITO, M.E.B. (Org). Urbanização e cidades: perspectivas geográficas. Presidente Prudente: [s.n.], 2001a. p. 606-643.

SPOSITO, M.E.B. Segregação socioespacial e centralidade urbana. In: VASCONCELOS, P. A.; CORRÊA, R. L.; PINTAUDI, S. M.; A cidade contemporânea. Segregação espacial. São Paulo: Contexto, 2013. p. 61-94.

SPOSITO, M. E. B.; SPOSITO, E. S. Articulação entre múltiplas escalas geográficas: lógicas e estratégias espaciais de empresas. Geousp - Espaço e Tempo (Online), v. 21, n. 2, 2017, p. 462-479. 
TAYLOR, P.; EVANS, D.; PAIN, K. Organization of the polycentric metropolis: corporate structures and networks. In: HALL, P.; PAIN, K. (Org.). The polycentric metropolis: learning from mega-city regions in Europe. Londres: Earthscan, 2006, p. 53-64.

VILLAÇA, F. Espaço intra-urbano no Brasil. São Paulo: Nobel, 1998. ISBN: 8575530755

WHITACKER, A. M. A produção do espaço urbano em Presidente Prudente: expansão/desdobramento da área central. Presidente Prudente, 1991. 318 f. Monografia (Bacharelado em Geografia) - Faculdade de Ciências e Tecnologia, Universidade Estadual Paulista, 1991.

WHITACKER, A. M. A produção do espaço urbano em Presidente Prudente: uma discussão sobre a centralidade urbana. 1997. 318 f. Dissertação (Mestrado em Geografia) - Faculdade de Ciências e Tecnologia, Universidade Estadual Paulista, Presidente Prudente, 1997. 